\title{
More support is needed for alternative agriculture information programs
}

The difficulty farmers have in getting reliable information on alternative farming methods from Extension and other traditional sources remains a serious problem in American agriculture. Extension workers are getting a lot more questions about alternative production methods and often don't know where to go to get reliable information.

This information gap was an important concern identified in the 1980 U.S. Department of Agriculture report on organic farming. USDA officials admitted in the late 1970s that they were receiving increasing numbers of requests for information and advice on organic farming practices and were unprepared to handle them. Little has changed since then.

Information on alternative agriculture still moves slowly, when it moves at all, through traditional channels. This problem persists even though more research is being done, the scientific literature on alternative agriculture is expanding, and more farmers are asking for information on alternative methods.

The usual way of dealing with an agriculture information gap is to turn to Extension for help. The USDA report, in fact, recommended developing information materials for county Extension agents "to assist them in providing services needed by organic farmers." Some progress has been made in Extension and elsewhere but burdget cuts and personnel layoffs, among other things, are making these gains more difficult.

Congress finally responded to this 1980 recommendation in the 1985 farm bill by adopting an agricultural productivity subtitle that authorizes USDA to spend money to disseminate this kind of information. But no money has been provided for implementation of the productivity subtitle and the outlook for a startup appropriation is not good.

\section{New developments}

There are some new developments, however, that should help get more of this information moving through traditional channels. The Ruth Mott Fund, for example, has provided funding to enable the Institute for Alternative Agriculture to publish a special edition of its monthly newsletter for Extension agents and specialists for one year. It will provide information on research reports and other published resources, on field days and other alternative agriculture events, and on educational initiatives by land grant universities and other institutions. It will include details on how to follow-up on these various sources for additional and more specific information.

The National Center for Appropriate Technology's effort to get money from Congress for a proposed technology transfer center has cleared the first hurdle. Authority for this new information dissemination approach was included in the 1985 farm bill and the House has included $\$ 500,000$ for a modest startup in its version of the USDA appropriations bill for Fiscal 1987. The center would disseminate information on cost-cutting, resource-conserving agricultural technologies to Extension agents and others.

Another developing source of information is the alternative agriculture tours, field days, and workshops that are being presented by land grant universities, the Regenerative Agriculture Association, state organic farming groups, and others. They give scientists an opportunity to report on research on alternative methods. They also provide organic farmers a chance to share information on how they make alternative methods work on the farm.

\section{Insufficient progress}

These developments are important breakthroughs in the longterm effort to get information out to those who want it. But they are no substitute for having information on alternative agriculture routinely available through the same publicly-supported channels that bring farmers the latest farm chemical recommendations.

This effort should continue until every farmer who wants reliable information on low-input resource-conserving methods can go to the local Extension office and other traditional sources of agricultural information and get help. This flow of reliable information is crucial if alternative agriculture methods are ever going to become a genuine option for all of America's farmers. 